\title{
Diesel Engine Fault Diagnosis with Vibration Signal
}

\author{
K. L. P Tharanga, Shuyong Liu, Shuai Zhang, Yuan Wang \\ College of Power Engineering, Naval University of Engineering, Wuhan, China \\ Email:1sydh@sina.com
}

How to cite this paper: Tharanga, K.L.P, Liu, S.Y., Zhang, S. and Wang, Y. (2020) Diesel Engine Fault Diagnosis with Vibration Signal. Journal of Applied Mathematics and Physics, 8, 2031-2042. https://doi.org/10.4236/jamp.2020.8915

Received: August 7, 2020

Accepted: September 26, 2020

Published: September 29, 2020

\begin{abstract}
When the vibration of diesel engine structure is measured, the signal is composed of a very complex superposition of the contributions of different vibratory sources modified by their respective transmission paths. These sources originate from several internal phenomenons in the engine such as combustion pressure variation, unbalanced reciprocating and rotating parts. In a diesel engine, movement parts work in a specific order. Once the starting point is determined, occurrence of work order in different cycle phases can be determined. This could successfully use to identifying of impulses in complex vibration signal of a diesel engine. From the variation of features of those impulses, it is possible to determine the working condition of the engine. This can use to fault diagnosis of diesel engine, specially faults related to combustion process.
\end{abstract}

\section{Keywords}

Vibration Monitoring, Valve Clearance, Valve Timing Diagram, Injection Fault

\section{Introduction}

Diesel engines are most widely used power plant in the world with wide range of applications. They convert chemical energy of diesel fuel into the mechanical energy which converts to useful work such as drive ships, vehicles, power generators, etc. Diesel engine is a mechanical device, so defects in mechanical systems due to various reasons are general phenomena. Therefore, engineers are doing continuous researches to find optimal fault detection system for diesel engine in order to monitor the health condition of the engine. Several types of signals can be measured for monitoring purpose including rotational angle speed [1], temperature [2], fuel and oil quality [3] [4], and vibration [5] [6] [7].

During the process of energy conversion in diesel engine, several parameters 
cause the engine to vibrate which significantly deteriorate the efficiency and service life of the engine. Vibration in a diesel engine occurs due to unidirectional combustion forces caused by the changes in gas pressure inside the cylinder, structural resonance and alternating inertia forces concentrated on different engine parts. The main moving components of engine are pistons, connecting rods, valves, cam shaft and crank shaft. Each impulse in vibration signal in the diesel engine could be determine using reference point. Therefore, vibration monitoring is a reliable method for detecting diesel engine abnormality, considering the fact that, various faults especially those related to combustion are the source of vibration [8].

Firing order, fuel timing, valve timing are some of popular topics when discuss about multi-cylinder diesel engines. This implies that many activities happening inside the engine has an order in time. In facts position of a piston, occurrence of firing in a cylinder, starting of fuel delivery to combustion chamber, opening and closing of valves can be given in degrees of crank angle referring to a cylinder. This can used to identify the vibration impulses related to activities in the engine and asses the condition of the engine. Many studies has been carried out on this regard and purpose of this paper is to provide an overview on co-relation of time order activities in diesel engines with vibration signatures and discuss effective ways of use vibration to fault detection in diesel engines based on literatures available on the topic.

\section{Vibration in Diesel Engine}

A diesel engine is powered by conversion of released energy from an air-fuel mixture, generated in fixed cylinders of the diesel engine, to the mechanical energy of rotating crankshaft. Due to parameters, such as unbalanced reciprocating and rotating parts, cyclic variation in gas pressure generated by the combustion process, misfire and inertia forces of the reciprocating parts significant levels of vibrations are induced in diesel engines. The vibration signals are categorized as torsional, longitudinal and mixed vibrations. Torsional vibrations are mainly caused by the exertion of cyclic combustion forces within the cylinder as well as the inertial forces of the rotating parts such as the crankshaft, camshaft and connecting rod. The pressure on the piston generates the tangential force that does useful work and increases the rotational speed of the crankshaft during the combustion stroke, whereas the compression stroke decreases the engine's angular velocity. The changing rotational speed results in the speed fluctuations of the crankshaft and induces the torsional vibrations at the crankshaft. The primary source of longitudinal vibration is the unbalanced forces acting on reciprocating and rotating components of the engine which propagate in three orthogonal directions [9]. Variation in the combustion pressure during the downward motion produce the unbalanced forces at the engine block and the unbalanced forces at the block are measured as longitudinal vibrations in the three orthogonal directions. 
Vibrations of a housing of diesel engine are not only the effect of processes occurring inside, but also the processes occurring outside the housing generated by the powertrain components and accessories. Each of these systems requires additional impacts influencing the vibroactivity of the housing not only directly but also indirectly by the mutual interaction between the individual elements. While analyzing the vibration signal of the engine housing the mutual non-linear relationship between the frequency response functions of particular elementary excitations cannot be omitted [10] [11] [12].

Since the engine block provides support for all the mechanisms making up the engine, it is subjected to dynamic interactions in all kinematic pairs. The vibrations of the block are a response to the total force acting in the places of its contact with moving parts of the engine. It is also important to take into the account the frequency response function between the places of generating extortions and a measuring point of vibration of the body. Knowledge of these relationships allows detecting disturbances of the signal which is the results of the emergence and development of damage of any of the components of the engine. It also allow for its proper identification.

In a diesel engine, different moving parts work in a specific order. Different cycle phases of work are strictly ordered. Once the starting point is determined, occurrence of work order in different cycle phases can be determined. A starting point could be easily determined using TDC position of a piston. In most diesel engines TDC position of piston is marked by OEM to ease the maintenance works. Even if it not marked; there are simple ways to determining TDC position of a piston. With this reference point and crank angle, it is possible to determine the occurrence of cyclic works such as combustion, valve opening and closing, fuel injection timing of the particular diesel engine. Therefore, if the starting point is determined, it is possible to assign the observed change of signal (Impulse) to the specified part of the cycle and to the specified kinematic pairs.

\section{Common Defects in Diesel Engines and Behavior of Vibration Impulse}

\subsection{Improper Valve Clearance}

Valve clearance of diesel engine is must to maintain its set value because it directly affects opening and closing timing of valves and the combustion quality of the diesel engine. Excessive valve clearance is one of a most common defect in diesel engine which can lead to serious defects if not properly repair at early stage. When valve clearance is more, the valve will open late and close early. If the clearance of intake valve is high, it results in getting less air to combustion chamber. This leads to low compression ratio, less power, improper combustion, less fuel economy, after burning and high carbon deposits inside the combustion chamber. If engine operates prolong time with excessive intake valve clearance will results in more and more power losses, sticky piston rings due to high carbon deposits which could results seizer of piston. Excessive valve clearance in exhaust 
valve leads to poor expelling of combustion products, power loss, diesel knocking, high working temperature, could result in catastrophic failure in engine.

An engine valve train is the device that controls the operation of valves. These usually consist of at least one intake valve and one exhaust valve for each cylinder in diesel engine. The valve train controls the intake air flow and exhaust gas flow of the combustion chamber. Valve gear mechanisms of diesel engines make wide use of cam drives of poppet valves. A common valve drive consists of a cam shaft, shaft bearings, a follower, a push rod, a rocker arm, a poppet valve with spring and rocker arm bearings. Due to their mass, the moving parts of the mechanism exert high loads on kinematic joints with the forces of inertia. Therefore valve mechanism possesses its own dynamic characteristics, which manifest themselves during engine operation. These characteristics are also influenced by the valve clearance.

The term valve clearance is stand for the total clearance in the valve timing gear. In common valve drive mechanism the numerical value of the clearance is measured between the valve stem and the sliding surface of its mating rocker arm. The need for valve clearance is due to the changing linear dimensions of the elements of valve timing gear mechanisms caused by their thermal expansions. Clearance value depends on engine type, the mode of cooling, valve timing gear design and numerous other factors.

Abnormal clearance of a valve train may be caused by incorrect positioning of the valve's rocker lever adjusting screw, excessive gross clearance in the valve tappet or a worn out or spall cam or its roller. Excessive valve clearance can be the cause of reduced engine power, the occurrence of additional impact forces of inertia, which lead to rapid wear of mating surfaces, resulting an uncontrolled increase in the clearance values, increasingly noisy operation of the valve timing gear and valve bounce during the closing of the valves [13].

Information about faults in the timing gear mechanism can be obtained from vibration signals of the engines cylinder head. Measurements of these signals are relatively simple and convenient. The possibility of diagnosing the operation of the timing gear by analyzing head vibration signals has been noticed and investigated by many researchers [14] [15] [16]. It has been found that these signals carry information about valve operation, excessive valve clearance, burning of valve seats, fractured valve springs, etc. [17].

Valve impact plays a significant role in the vibration of diesel engines. The valve impacts on the valve seat at valve closure and the degree of impact depends on the valve closing velocity, which is controlled by the dynamic behavior of the valve train, particularly the force exerted on the valve by the valve spring. The valve is loaded by a spring and the cylinder pressure, which varies periodically during engine operation [18]. The relationship between the valve clearance and amplitude of vibration impulse during valve opening and closing is presented in Figure 1. As valve clearance increases the amplitude or the strength of the impulse caused by the valve opening and closing increases. 


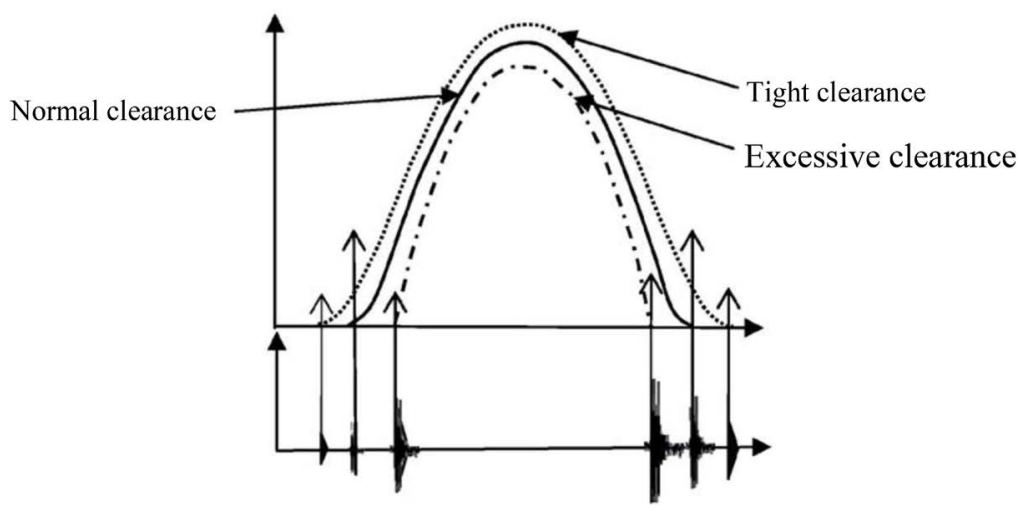

Figure 1. Comparison of valve clearance and amplitude of vibration impulse [24].

When the clearance of valve train increases, the time for valve opening lags and that for valve closing advances. When the valve train has excessive clearance, the energy of vibration induced during valve opening and closing increases. The time of valve opening is delayed and time of valve closing is advanced. These time events in terms of the crank angle, which are due to excessive valve train clearance, change according to the condition of valve train, but not working condition of the diesel engine [19]. Therefore, valve impact impulse to be analyzing in terms of the occurrence time in the crank angle domain and signal energy at same operating condition of the diesel engine for better evaluation of working condition of the valve.

Valve timing diagram of a diesel engine provides all details of opening and closing of valves referring to position of the piston. Hence, the position of valve opening or closing can be determined related to crank angle. Therefore when the reference point is given, timing of valve opening and closing is known in crank angle domain. Vibration of cylinder head can be measured in time domain using accelerometer and same time domain vibration signal can be resampled to crank angle domain signal. Using details available in valve timing diagram of the engine it is possible to determine impulse related to valve opening and closing in vibration signal of crank angle domain.

\subsection{Piston Slap}

The cylinder liner-piston ring is one of the most important rubbing pairs of the internal combustion engine, whose tribological condition has great influence on engine power, reliability, durability, economy and emissions. The piston assembly plays a key role in the generation of engine mechanical losses, including noise well known as piston slap. Piston slap is a common impact phenomenon in diesel engines and is one of the main sources of transversal vibration in such engines. The piston with high speed motion and complicated kinematic characteristics, are particularly vulnerable to the harsh engine operating conditions. Under the condition of an external shock load or contaminated lubricant, metal to metal contact between the piston and the liner wall can occur and will lead to excessive wear and quickly create oversized clearances. With oversized clear- 
ances, the impact forces between the piston and cylinder liner wall increase greatly, which further accelerates the wear.

As described above, piston slap is one of the most characteristic sources of engine body vibrations. Intensity of that excitation and its vibration for different engine cycles depends mainly on in cylinder pressure alterations. Changes of piston slap force value, influencing the piston horizontal movement results also from following factors [20]. Piston, piston pin, connecting rod mass; Dimensions and the geometry of crank-connecting rod mechanism; Engine crankshaft angle; Engine speed and load; Piston skirt clearance.

The vibration response of piston slap has a strong relationship with the clearance between the piston rings and the cylinder liner as well as with the magnitude of the side thrust force that act against the piston and cylinder. The different sizes of clearance between the piston ring and piston liner create different time events and energy content in the induced vibration. However, the amplitude of transversal vibration is rather small and is usually emerged in the larger vibrations induced by other components. For example, the combustion process of cylinder can create large vibrations, which may overwhelm the vibration induced by piston slap.

The piston leaves the side of the inner wall it was previously held against and moves to the other side of the cylinder wall. This movement has also been called the secondary movement of the piston. In order to better study the occurrence of slap noise events, one should carefully monitor the piston secondary motion which leads to skirt to cylinder liner contacts. The forces and moments acting on the piston are responsible for the secondary motion, which occurs laterally within the clearance and around the piston pin. When the crankshaft rotation is clockwise, the left side of the cylinder liner is called the thrust side and the opposite side is known as the anti-thrust side. Piston impact can occur on either side of the liner. If the lateral acceleration of the piston induced by the transverse force is large enough and the interval until the next time the force direction changes is long enough, the piston will move across the clearance and collide against the opposite side of the cylinder wall. The impact will the excite vibration of the engine block and cause structure born noise around the engine.

It is crucial to monitor condition of the cylinder liner-piston assembly system in a reliable and timely manner which can detect undergoing faults in time to ensure the normal operation of the diesel engine. Additionally, it is very significant to extend the work reliability and life of cylinder liner-piston rings, improve the efficiency of diesel engine and fuel economy and prolong service life through the condition monitoring of cylinder liner-piston rings. Past researchers have attempted to determine the exact position of piston slap events during the engine cycle and correlate them to the engine block vibration response. Combustion and piston impact are difficult to separate since their noise levels are of the same order. Moreover, they occur almost at the same time in the vicinity of the TDC and are highly co-related. Only few papers show how to separate the me- 
chanical faults and combustion faults by means of the measured vibration signals, extracting suitable features from the vibration signals for the detection of different faults is a critical stage in developing comprehensive condition monitoring system. Spectrofilter to implement the impact-source separation [21], wavelet decomposition and fast reconstruction algorithm [22], blind source separation of vibration components [23] are some of methods to separate piston slap events from combustion vibration.

Researchers [22] studied the piston slap phenomenon inside the reciprocating engine from experiments and then proposed simulation model to predict the slap induced vibration response and analyzed the relationship between the piston slap faults and speed, load and clearance sizes. Another research used the range angle empirical mode decomposition method to extract the vibration induced by piston slap for oversized clearance [24]. Vibration signal of diesel engine and signal processing method-empirical mode decomposition has been successfully used to extract the features of vibration signals of diesel engine with piston slap fault. With the help of simulation and experiment methods an advanced diagnostic system for piston slap fault investigated using artificial neural network, [25] based on the non-stationary characteristics of diesel engine vibration. Vibration signals of normal condition of engine and fault condition with piston slap fault were experimented and proved simulated data with experiment results.

All the experiments have used crankshaft encoder signal to determine the TDC position of the piston since impact of piston slap event is maximum near the TDC at combustion stroke of the diesel engine. However, advanced signal processing methods, feature extraction of vibration signal and fault classification methods have to use for identify the piston slap event with the help of crank angle or the piston position obtained by the crank encoder signal.

\subsection{Fuel Injection Faults}

The fuel injection system is one of diesel engine's key equipment, its work quality influence to diesel engine's work process and the machine's performance immediately, it decide diesel engine's efficiency and reliability. The pertinent data indicated that in the diesel engine's faults, the fuel injection system faults occupy $27 \%$ above. The diesel engine fuel injection system's condition examination and the fault diagnosis technology is the base to appraise the diesel engine fuel injection system's condition and function. Therefore, it has remarkable economic efficiency to the diesel engine fault injection system's condition examination and fault diagnosis researches [26].

Injection faults due to defects in fuel injection pump, fuel lines and injector affect the power of engine, increase the polluting particles in the exhaust gas, increase the radiated noise and reduce the life cycle of the engine. Higher injection pressure increases the pollutants in the emission and increase fuel consumption. A lower pressure however, reduces the engine power and efficiency [27]. 
In the internal combustion engines, and in particularly in diesel engines, the combustion development is strongly depends on the injector parameters, such as injection pressure and timing. The injection of diesel fuel under a high pressure during a very short time creates a mechanical shock. It can be claimed that a strict relationship exists between the way the thermal energy is released and how this energy propagates through gases and is transmitted to the cylinder walls and the engine surface. Monitoring the surface vibration should allow to derive information about the combustion development and quality [28]. Furthermore, the spring of the needle of each fuel injector is also a source of secondary importance contributing to cylinder head vibration.

Fuel injector needle valve is a major critical component which to guarantee fuel spray characteristic. In fuel injection termination, the injector needle valve rapidly drops and produces impact stress to the needle valve seating [29]. By analyzing needle valve crash vibratory response signal can get information of fuel injection system condition. The time information and strength information are described by characteristics extracted from cylinder head vibration signal and the characteristics are used to diagnose fuel injection system faults.

Fuel injection process includes two sections [30]; needle valve opening and needle valve closing. The needle valve exist double crash phenomenon in actual work. So, direct threshold detection and peak detection may not be able to get accurate needle valve closing timing from valve crash vibratory response signal. Peak and total energy of valve crash vibratory signal can both describe the strength of valve crash, but due to the cylinder combustion pressure, energy statics can't avoid combustion vibratory response signal influence.

Needle valve closing timing detection must in the work condition when needle valve closing has interval with combustion process in time domain. When diesel engine is loaded up, the fuel injection continuance rises and injector needle valve closing lags. Valve closing timing decreases while load up under the same rotational speed which is correspondence with fuel injection continuous rises. When rotational speed up due to the injection lag rises, the actual injection timing lags and valve closing timing lags. Valve closing time decrease while rotational speed up under the same load.

Common injector faults and behavior of vibration response signal due to those faults can be described as follows [30]. Needle opening pressure decline. Needle valve crash kinetic energy is mainly affected by injector spring stiffness and fuel pressure. When spring stiffness decreases, the crash kinetic energy rises. When fuel pressure lifts the crash kinetic energy creases. Besides needle valve crash, the fuel rapid pressure fluctuations and unsteady cavitation inside high pressure diesel engine nozzle [31] will excite cylinder head vibration. But its strength is much feebler than needle valve crash vibratory response. As diesel engine life time services, needle opening pressure will decline due to spring elastic force decrease. Crash kinetic energy rises while spring stiffness decrease. The vibration peak characteristics that describe valve crash strength increases under 
opening pressure decline state which is correct correspondence with crash kinetic energy rises.

Needle valve close loosens. As fuel injector life time service, needle valve close looses and leaks oil impurity. In this condition, injected fuel mass quantity decreases, oil injection continuance declines, injector needle valve closing advances and actual fuel pressure declines. Vibration peak characteristics that describe valve crash strength decreases correspondence with actual fuel pressure decline.

Commencement of fuel supply advanced. Misalignment can cause commencement of fuel pressure advanced. In this condition, commencement of fuel injection advances and needle valve closing timing advances. Vibration peak characteristics that describe valve crash strength increases.

Cylinder misfire. When misfire occurs, performance suffers along with fuel economy, power output, emissions and efficiency of combustion. The diagnosis of fault related to misfire can be carried out by analyzing the combustion pressure, directly measured by pressure transducers [32]. However the cost of fitting each cylinder with a pressure transducer is prohibitive. Structure born vibration due to combustion is much effective and cheap intrusive method to estimate the cylinder pressure. In this condition, fuel injector doesn't have any event. Vibration peak characteristics that describe valve crash strength decreases.

It is prudent that cylinder head vibration signal and surface vibration signal can be used to diagnosis the fuel injector faults as well as combustion faults. However, injector valve crash vibratory response signal is much smaller compare to the combustion vibratory response signal. Therefore, time event of occurring of valve crash to be used to identify the crash vibratory signal. Fuel timing diagram of particular engine give the related crank angle which fuel injection commenced and terminated referencing to the TDC position of particular piston. Therefore, analyzing of cylinder head vibration signal in crank angle domain will ease the identification of impulse related to injector valve crash.

\section{Conclusions}

Diesel engines are subjected to vibration due to unbalanced reciprocating and rotating parts, cyclic variation in gas pressure generated by the combustion process, misfire and inertia forces of the reciprocating parts. Since the engine block provides support for all the mechanisms making up the engine, it is subjected to dynamic interactions in all kinematic pairs. The vibrations of the block are a response to the total force acting in the places of its contact with moving parts of the engine. The vibration response signal of the diesel engine is non-stationery and non-linear in nature which raise requirement of additional parameter for analyzing the signal.

In a diesel engine, systems are work in a specific order. Different cycle phases of work are strictly ordered. Once the starting point is determined, occurrence of work order in different cycle phases can be determined. TDC position of a piston is the most suitable starting point since many work orders such as fuel tim- 
ing, valve timing and combustion refer the TDC position of piston. Impulses in vibratory response signal could be identify using reference point and valve timing diagram, fuel timing diagram and firing order of the particular engine. Change in such impulse in timing and its amplitude gives the information about changes in working process. Therefore, work order of a diesel engine is very important to fault diagnosing using vibration of the engine. Many scientists have done research on fault diagnosis of diesel engine using vibration signal in angle domain and obtained successful results.

\section{Conflicts of Interest}

The authors declare no conflicts of interest regarding the publication of this paper.

\section{References}

[1] Li, Z., Yan, X., Yuan, C. and Peng, Z. (2012) Intelligent Fault Diagnosis Method for Marine Diesel Engine Using Instantaneous Angular Speed. Journal of Mechanical Science Technology, 26, 2413-2423. https://doi.org/10.1007/s12206-012-0621-2

[2] Assanis, D.N. and Friedmann, F.A. (1933) A Thin Film Thermo Couple for Transient Heat Transfer Measurements in Ceramic Coated Combustion Chambers. International Communications in Heat and Mass Transfer, 20, 459-468. https://doi.org/10.1016/0735-1933(93)90058-4

[3] Albarbar, A., Gu, F. and Ball, A. (2010) Diesel Engine Fuel Injection Monitoring Using Acoustic Measurements and Independent Components Analysis. Measurements, 43, 1376-1386. https://doi.org/10.1016/j.measurement.2010.08.003

[4] Wang, Y., Zhang, F., Cui, T. and Zhou, J. (2016) Fault Diagnosis for Manifold Absolute Pressure Sensor of Diesel Engine Based on Elman Neural Network Observer. Chinese Journal of Mechanical Engineering, 29, 386-395. https://doi.org/10.3901/CJME.2015.1211.145

[5] Da yong N, Chang le S, Youngjun G, Zengmeng Z and Jiaoyi H. (2016) Extraction of Fault Components from Abnormal Sound in Diesel Engine Using Acoustic Signals. Mechanical Systems and Signal Processing, 75, 544-555. https://doi.org/10.1016/j.ymssp.2015.10.037

[6] Moosavian, A., Najafi, G., Ghobadian, B., Mirsalim, M., Jafari, S.M. and Sharghi, P. (2016) Piston Scuffing Faults and It's Identification in an IC Engine by Vibration Analysis. Applied Acoustics, 102, 40-48. https://doi.org/10.1016/j.apacoust.2015.09.002

[7] Chen, J., Randall, R.B. and Peeters, B. (2016) Advance Diagnostic System for Piston Slap Faults in IC Engine, Based on the Non-Stationary Characteristics of the Vibration Signal. Mechanical Systems and Signal Processing, 75, 434-454. https://doi.org/10.1016/j.ymssp.2015.12.023

[8] Taghizahed-Alisaraei, A., Ghobadian, B., Tavolcoli-Hashin, T., Mohtasebi, S.S., Rezaei-asl, A. and Azadbakht, M. (2016) Characterization of Engine's Combustion Vibration Using Diesel and Bio Diesel Fuel Blends by Time Frequency Method. A Case Study. Renewable Energy, 95, 422-432. https://doi.org/10.1016/j.renene.2016.04.054

[9] Ramachandran, T. and Padmanaban, K.P. (2012) Review on Internal Combustion Engine Vibration and Monitoring. International Journal of Engineering and Science, Emerging Technology, 3, 63-73. 
[10] Madej, H. and Czech, P. (2008) Attempt to Utilize Histogram of Vibration Cepstrum of Engine Body for Setting up the Clearance Model of the Piston-Cylinder Assembly for PNN Neural Classifier. Journal of KONES, Powertrain and Transport, 15.

[11] Merkisz, J. and Mazurek, S. (2007) On-Board Diagnosis System of Cars. Transport and Communication Publishers, Warsaw.

[12] Rokosch, V. (2007) Fumes Cleaning Systems and On-Board Diagnostic System of OBD Cars. Transport and Communication Publishers, Warsaw.

[13] Lukasz, J., Jacek, C., Leszek, K., Slawomir, W. and Franstisek, B. (2015) Application of Vibration Signal in the Diagnosis of IC Engine Valve Clearance. Journal of Vibroegineering, 17, 175-181.

[14] Bi, F. and Song, Z. (2013) Fault Diagnosis of Valve Train of Internal Combustion Engine Based on the Artificial Neural Network and Support Vector Machine. Advance Material Research, 605-607, 729-733. https://doi.org/10.4028/www.scientific.net/AMR.605-607.729

[15] Czech, P. (2013) Intelligent Approach to Valve Clearance Diagnosis in Cars. Communications in Computers and Information Science, 395, 384-391. https://doi.org/10.1007/978-3-642-41647-7 47

[16] Figlus, T. and Liscak, S. (2014) Assessment of the Vibroactivity Level of SI Engines in Stationary and Non-Stationary Operating Conditions. Journal of Vibroengineering, 16, 1349-1359.

[17] Wang, C., Zang, Y. and Zong, Z. (2008) Fault Diagnosis for Diesel Valve Trains Based on Time-Frequency Images. Mechanical Systems and Signal Processing, 22, 1981-1993. https://doi.org/10.1016/j.ymssp.2008.01.016

[18] Fathi, E., Yibo, F., Fengshou, G. and Andrew, B. (2010) Diesel Engine Valve Clearance Detection Using Acoustic Emission. Advances in Mechanical Engineering.

[19] Yujun, L., Peter, W., Xin, Y. and Jianguo, Y. (2010) EMD Based Fault Diagnosis for Abnormal Clearance between Contacting Components in a Diesel Engine. Mechanical Systems and Signal Processing, 24, 193-210. https://doi.org/10.1016/j.ymssp.2009.06.012

[20] Marek, F., Pauel and Rafal, S. (2014) Estimation of Engine Piston Pin Wear Using Time-Frequency Method. JVE International, 159-163.

[21] Pruvost, L., Leclere, Q. and Parizet, E. (2009) Diesel Engine Combustion and Mechanical Noise Separation Using an Improved Spectrofilter. Mechanical Systems and Signal Processing, 23, 2072-2087. https://doi.org/10.1016/j.ymssp.2009.04.001

[22] Geng, Z. and Cheng, J. (2005) Investigation in to Piston Slap Induced Vibration for Engine Condition Simulation and Monitoring. Journal of Sound and Vibration, 282, 735-751. https://doi.org/10.1016/j.jsv.2004.03.057

[23] Antoni, J. (2005) Blind Separation of Vibration Components. Principles and Demonstrations. Mechanical System and Signal Processing, 19, 1166-1180. https://doi.org/10.1016/j.ymssp.2005.08.008

[24] Li, Y.J., Tse, P.W. and Yang, X. (2010) EMD Based Fault Diagnosis for Abnormal Clearance between Contacting Components in a Diesel Engine. Mechanical Systems and Signal Processing, 24, 193-210. https://doi.org/10.1016/j.ymssp.2009.06.012

[25] Jian, C. and Robert, B.R. Advanced Diagnostic System for Piston Slap Fault in IC Engines Based on the Non-Stationary Characteristics of the Vibration Signal. Project No. LP0883486; Surveillance 7 Conference, France.

[26] Zhang, B., Yan, S. and Tian, C. (2008) Study on Fault Diagnostic System of Diesel 
Engine Fuel Injection System Based on BP Neural Network. ISECS International Colloquium on Computing, Communication, Control and Management, 108-112. https://doi.org/10.1109/CCCM.2008.33

[27] Celikten, I. (2003) An Experimental Investigation of the Effect of the Injection Pressure on Engine Performance and Exhaust Emission in Direct Ignition Diesel Engine. Applied Thermal Engineering, 23, 2051-2060.

https://doi.org/10.1016/S1359-4311(03)00171-6

[28] Carlucci, A.P., Chiara, F.F. and Laforgia, D. Block Vibration as a Way of Monitoring the Combustion Evolution in a Direct Injection Diesel Engine. SAE Technical Paper Series. 2006-01-1532 https://doi.org/10.4271/2006-01-1532

[29] Yao, C. (1989) Relation between Diesel Injector Needle Valve Opening Pressure and Shock Stress on Its Seat. Transactions of CSICE, 17, 279-286.

[30] Liu, J., Shi, Y., Zhang, X., Xu, S. and Dong, L. (2011) Fuel Injection System Fault Diagnosis Based on Cylinder Head Vibration Signal. Procedia Engineering, 16, 218-233. https://doi.org/10.1016/j.proeng.2011.08.1075

[31] Wang, X. and Su, W. (2010) Analysis on Pressure Fluctuation and Unsteady Cavitation inside High Pressure Diesel Injector Nozzle. Transactions of CSICE, 28, 193-198.

[32] Stancovic, L.J. and Bohme, J.E. (1999) Time Frequency Analysis of Multiple Resonances in Combustion Engine Signal. Signal Processing, 79, 11-28.

https://doi.org/10.1016/S0165-1684(99)00077-8 